\title{
EDITORIAL
}

\section{Industria 4.0: hacia la electrificación de la energía}

Desde el origen de la humanidad el requerimiento energético ha sido uno de los problemas fundamentales de la sociedad; basta recordar que por millones de años el hombre fue cazador y recolector para satisfacer sus propias necesidades energéticas.

Un punto de inflexión en la evolución de la humanidad fue el surgimiento de la sociedad industrial. El mundo comenzó a transformarse con una rapidez nunca vista en la historia, fundamentalmente por la mayor capacidad para realizar trabajo; en esta época, en forma de energía térmica convertida en mecánica gracias al motor de combustión. Los caballos de vapor reflejan el impacto de este cambio; por ejemplo, un motor de $100 \mathrm{CV}$ podía hacer el mismo trabajo que 100 caballos.

El resultado, fue una verdadera revolución y dio origen a la industrialización, las fábricas, la generación de empleo y con ello a la economía y el desarrollo; sin embargo, también a las desigualdades y al uso masivo de recursos naturales.

En el inicio de la revolución industrial, denominada Industria 1.0, los motores eran alimentados por carbón como uno de los principales combustibles; no obstante, el auge industrial motivó la búsqueda de procesos de conversión más eficientes, debido a los bajos rendimientos relativos de las máquinas de combustión.

En este contexto, como una alternativa de mayor eficiencia, surge la energía eléctrica y muchas máquinas de combustión comienzan a cambiarse por motores eléctricos, lo que conduce a la industria 2.0 con una masificación de los sistemas eléctricos de potencia y un fuerte auge tecnológico; ya no solo para la industria sino también para el bienestar de las personas. Sin embargo, todo ello provoca un fuerte incremento del consumo energético, que sigue siendo sustentado por combustibles fósiles, agregándose a la matriz energética de la época el petróleo y el gas.

El auge de la electrónica y el consecuente desarrollo de las tecnologías de la información y las comunicaciones (TIC's) consolidan el crecimiento industrial, naciendo así la denominada industria 3.0 y con ello la era de los objetos: televisores, computadores, satélites y múltiples dispositivos electrónicos para todo tipo de aplicaciones. La masificación de estos dispositivos y el posterior surgimiento de las redes de información crean nuevamente un fuerte incremento de los requerimientos energéticos del planeta.

Junto con el requerimiento de energía eléctrica, el desarrollo del transporte y diversos procesos térmicos causan que los combustibles fósiles se transformen en la base del abastecimiento energético del planeta, asî lo señala la Agencia Internacional de Energía (AIE) que indica que el suministro total de energía primaria en el 2017 fue abastecido en un $81 \%$ por combustibles fósiles, donde el petróleo constituye el 32\%, el carbón el $27 \%$ y el gas el $22 \%$.

Esta realidad no es sustentable, tanto por la inevitable desaparición de los combustibles fósiles como por los efectos adversos que generan, principalmente desde el punto de vista medio ambiental.

Por otro lado, el desarrollo industrial sigue creciendo y poco a poco van instalándose en el mundo los denominados sistemas inteligentes, quizá el mejor ejemplo es la Smart City, un nuevo paradigma que ya no fija el desarrollo de nuevos objetos, sino que como lo dice Fritjof Capra "una sociedad donde los objetos ya no son lo importante, sino las relaciones entre ellos", comenzando así el surgimiento de la denominada Industria 4.0, donde los sistemas ciber físicos y la digitalización permitirán la creación de un nuevo lenguaje 
de comunicación entre objetos y su entorno, posibilitando el desarrollo de una gran cantidad de nuevas aplicaciones inteligentes.

El impacto de estos sistemas inteligentes en la vida diaria será tremendo, estimándose que los 23 billones de dispositivos actualmente conectados (2018) se incrementarán a 75 billones en el 2025 (IHS, Statista 2018); dicho de otra forma, en el 2025 cada persona tendrá en promedio diez dispositivos conectados, todos los cuales inevitablemente demandarán más energía; constituyéndose, por lo tanto, un escenario futuro donde el requerimiento energético seguirá incrementándose.

Unido a lo anterior, está el hecho que la escasez de combustibles fósiles afectará críticamente al transporte, altamente dependiente de esta fuente energética. Razón, por la cual la electro movilidad comenzará a ser protagonista, lo cual muestra a futuro un mayor incremento de la energía eléctrica en la matriz energética del planeta.

En este escenario, el descubrimiento de nuevas fuentes energéticas y procesos de conversión parece urgente; sin embargo, a la fecha no se vislumbra ningún proceso de conversión más óptimo que la energía eléctrica, pero es fundamental, como lo indica la AIE, comenzar a "promover políticas energéticas sustentables que estimulen el crecimiento económico y la protección ambiental en un contexto mundial; sobre todo, en cuanto a reducir las emisiones de gases de efecto invernadero que contribuyen al cambio climático" (AIE 2018).

En consecuencia, en esta nueva sociedad liderada por la industria 4.0 la tendencia parece ser clara a la electrificación de la energía, pero con un fuerte incremento de generación sustentable con el medio ambiente como las energías renovables, el desarrollo de nuevos sistemas de almacenamiento de energía, como nuevas baterías y celdas de combustibles, y el uso eficiente de la energía a través de los nuevos sistemas inteligentes como smart grid, smart meter, smart home, entre otros, que buscan que el usuario final no solo sea un consumidor, sino un elemento activo del sistema, quizá el más relevante para efectivamente lograr un crecimiento ambiental, social y económico sostenible.

Cómo se observa, el mundo ha evolucionado, desde la era de las cavernas a los hogares inteligentes, pero desde el punto de vista energético el problema sigue siendo el mismo.

\author{
Dr. Horacio Díaz Rojas \\ Universidad de Tarapacá \\ Escuela Universitaria de Ingeniería Eléctrica-Electrónica \\ Arica, Chile,hdiaz@uta.cl
}

